Check for updates

Cite this: RSC Adv., 2017, 7, 27079

\title{
Oxygen-vacancy-promoted catalytic wet air oxidation of phenol from $\mathrm{MnO}_{x}-\mathrm{CeO}_{2}^{\dagger}$
}

\author{
Changjian Ma, ${ }^{a}$ Yaoyao Wen, ${ }^{a}$ Qingqing Yue, ${ }^{a}$ Anqi Li, ${ }^{a}$ Jile Fu, ${ }^{a}$ Nouwei Zhang, ${ }^{\text {*a }}$ \\ Hengjun Gai, ${ }^{b}$ Jinbao Zheng ${ }^{a}$ and Bing $H$. Chen (D) *a
}

\begin{abstract}
Catalytic oxidation can be effectively promoted by the presence of oxygen vacancies on the catalyst surface. In this study, the effect of oxygen vacancies on the catalytic wet air oxidation (CWAO) of phenol was investigated with $\mathrm{CeO}_{2}$ and $\mathrm{MnO}_{x}-\mathrm{CeO}_{2}$ as catalysts. $\mathrm{CeO}_{2}$ and $\mathrm{MnO}_{x}-\mathrm{CeO}_{2}$ catalysts with different amounts of oxygen vacancies were obtained via hydrothermal methods and applied for the CWAO of phenol. It was found that $\mathrm{CeO}_{2}$ and $\mathrm{MnO}_{x}-\mathrm{CeO}_{2}$ nanorods were much more active than the cubic nanorods. The physicochemical properties of the samples were characterized by TEM, XRD, BET, XPS, and $\mathrm{H}_{2}$-TPR techniques. The results revealed that the presence of oxygen vacancies in $\mathrm{CeO}_{2}$ and $\mathrm{MnO}_{x}-$ $\mathrm{CeO}_{2}$ catalysts could increase the oxidizing ability of the catalysts surface. The addition of $\mathrm{Mn}$ could greatly improve the adsorption ability of $\mathrm{CeO}_{2}$ and more efficiently oxidize phenol and its intermediates. The synergy between $\mathrm{Mn}$ and $\mathrm{Ce}$ could further improve the catalyst redox properties and produce a larger amount of active oxygen species, which is the reason why $\mathrm{MnO}_{x}-\mathrm{CeO}_{2}$ nanorods are the most active catalysts among the catalysts investigated in this study.
\end{abstract}

Received 9th April 2017

Accepted 8th May 2017

DOI: $10.1039 / \mathrm{c} 7 \mathrm{ra04037g}$

rsc.li/rsc-advances

proper catalysts. ${ }^{8,9}$ Clearly, developing a suitable catalyst

\section{Introduction}

Phenol and its derivatives can be found as by-products from a variety of sources such as chemical, petrochemical, pharmaceutical and coal chemical industries. ${ }^{1,2}$ Since phenol is highly toxic to aquatic life, it would result in a severe impact on water resources if phenol-contaminated streams are discharged without treatment. ${ }^{3}$ Biotreatment is often applied in water treatment; however, phenol can inhibit the activity of microbes, causing biotreatment to be impractical for phenolic wastewater. ${ }^{4}$ Catalytic wet air oxidation (CWAO) has been shown to be an effective and environmentally friendly way to remove refractory organic compounds, such as dyes, phenol, and succinic acid as normally no additions other than oxygen/air are needed for the process..$^{5-7}$ Under an oxygen or air atmosphere at relatively elevated temperatures and pressures, refractory organic compounds can be completely oxidized into $\mathrm{CO}_{2}$ and $\mathrm{H}_{2} \mathrm{O}$ or partially converted to other less toxic compounds by

\footnotetext{
${ }^{a}$ Department of Chemical and Biochemical Engineering, National Engineering Laboratory for Green Chemical Productions of Alcohols-Ethers-Esters, College of Chemistry and Chemical Engineering, Xiamen University, Xiamen 361005, PR China.E-mail:zhnw@xmu.edu.cn; chenbh@xmu.edu.cn

${ }^{b}$ Qingdao University of Science and Technology, Qingdao 266042, Shandong, China $\uparrow$ Electronic supplementary information (ESI) available: HRTEM images of $\mathrm{CeO}_{2}$ 110 surface, XRD patterns of $\mathrm{MnO}_{x}$ catalysts; phenol and TOC conversions on $\mathrm{MnO}_{x}-\mathrm{CeO}_{2}$ nanorods and nanocubes at various temperatures; phenol and TOC conversions on $\mathrm{MnO}_{x}-\mathrm{CeO}_{2}$ nanorods and nanocubes at various pressures. See DOI: $10.1039 / \mathrm{c} 7 \mathrm{ra} 04037 \mathrm{~g}$
} essential for CWAO processes.

Among the various catalysts investigated for the CWAO of phenol in the reported literature, the cerium-incorporated manganese oxide composite $\left(\mathrm{MnO}_{x}-\mathrm{CeO}_{2}\right)$ catalyst has been identified as one of the most promising catalysts. ${ }^{10}$ It was reported that $\mathrm{MnO}_{x}-\mathrm{CeO}_{2}$ is an effective catalyst for the CWAO of ammonia, poly(ethylene)glycol, acetic acid, pyridine, etc. ${ }^{11,12}$ Arena reported a new "redox-precipitation" route to synthesis the $\mathrm{MnO}_{x}-\mathrm{CeO}_{2}$ catalyst resulting in improved catalytic activity. ${ }^{13}$ It was also reported that formic and acetic acids are the common intermediates during the CWAO of phenol, and that the adsorption of formic and acetic acids was driven by electrostatic interactions with the $\mathrm{MnO}_{x}-\mathrm{CeO}_{2}$ surface. ${ }^{14,15}$ The surface reaction between the adsorbed intermediates and the activated oxygen species is the rate-determining step. ${ }^{16}$ Furthermore, it was reported that the interaction between Mn and $\mathrm{Ce}$ is beneficial for the CWAO of ammonia, ${ }^{11}$ where a physical mixture of $\mathrm{Mn}_{2} \mathrm{O}_{3}$ and $\mathrm{CeO}_{2}$ was far less active than that of $\mathrm{Mn} / \mathrm{Ce}$ catalysts. The above information shows the merits of $\mathrm{MnO}_{x}-\mathrm{CeO}_{2}$ catalysts in the field of CWAO; however, less attention has been paid to the physicochemical properties of $\mathrm{MnO}_{x}-\mathrm{CeO}_{2}$ catalysts, such as the effect of oxygen vacancies on the CWAO of phenol.

Our previous study showed that $\mathrm{O}_{2}$ activation ability can directly affect the performance of $\mathrm{CO}$ oxidation. ${ }^{17}$ The activation of oxygen can form superoxo $\left(\mathrm{O}^{2-}\right)$ and/or peroxo $\left(\mathrm{O}_{2}{ }^{2-}\right)$ species, which are more oxidative than molecular oxygen $\left(\mathrm{O}_{2}\right)$. Active oxygen species can be formed on the surface of ceria in propane 
oxidation passing via a Mars and van Krevelen mechanism. ${ }^{18}$ Molecular oxygen prefers to fill the ceria oxygen vacancies to produce activated oxygen species. ${ }^{19}$ High oxygen vacancy concentrations can also assist the cycle transition between $\mathrm{Ce}^{3+}$ and $\mathrm{Ce}^{4+}$ ions $\left(\mathrm{Ce}^{3+} \leftrightarrow \mathrm{Ce}^{4+}\right)$, which is the key for many catalytic activities.

There are several ways to create oxygen vacancies. In the literature, both ceria (110) and (100) surfaces have been reported as having superior oxygen storage ability than the (111) surface. ${ }^{20}$ However, the ceria (100) surface contains less oxygen vacancies than the (110) surface. ${ }^{21}$ This property of the ceria (110) surface causes the improved catalytic activity for CO oxidation and soot combustion. ${ }^{22,23}$ Doping various metals into ceria is another way to create oxygen vacancies. As $\mathrm{Mn}$ and Ce have a tendency to form solid solutions, ${ }^{24,25}$ doping Mn into the ceria lattice can greatly increase oxygen mobility and also help to produce oxygen vacancies on a catalyst's surface. ${ }^{26}$ When the atomic ratio of $\mathrm{Mn}: \mathrm{Ce}$ is less than 1 , all the $\mathrm{MnO}_{x}-\mathrm{CeO}_{2}$ catalysts possess the fluorite cubic structures of $\mathrm{CeO}_{2} \cdot{ }^{27}$ Thus, doping $50 \% \mathrm{Mn}$ atoms into $\mathrm{CeO}_{2}$ is expected to produce the maximum amount of oxygen vacancies.

In order to study the effect of oxygen vacancies on the CWAO of phenol, we synthesized $\mathrm{CeO}_{2}$ nanorods and nanocubes using hydrothermal methods. To further confirm the effect of oxygen vacancies on the CWAO of phenol, 50\% Mn in a molar ratio was doped into $\mathrm{CeO}_{2}$ nanorods and nanocubes to form $\mathrm{MnO}_{x}-\mathrm{CeO}_{2}$ nanorods and nanocubes. Characterizations, including XRD, $\mathrm{H}_{2}$ temperature-programmed reduction $\left(\mathrm{H}_{2}-\mathrm{TPR}\right)$, XPS, and TEM, were performed to link the physicochemical properties and catalytic performance. The results revealed that the oxygenvacancy-related properties as well as the synergy between Mn and Ce are the key for the high activities in the CWAO of phenol.

\section{Experimental}

\subsection{Preparation of the catalyst}

2.1.1 Chemicals. Cerium(III) nitrate hexahydrate $\left(\mathrm{Ce}\left(\mathrm{NO}_{3}\right)_{3} \cdot 6 \mathrm{H}_{2} \mathrm{O}\right)$, manganese(II) chloride tetrahydrate $\left(\mathrm{MnCl}_{2}\right.$ $\left.\cdot 4 \mathrm{H}_{2} \mathrm{O}\right)$, phenol $\left(\mathrm{C}_{6} \mathrm{H}_{6} \mathrm{O}\right)$, potassium permanganate $\left(\mathrm{KMnO}_{4}\right)$, manganous nitrate, $50 \%$ solution $\left(\mathrm{Mn}\left(\mathrm{NO}_{3}\right)_{2}\right)$, and acetonitrile $\left(\mathrm{C}_{3} \mathrm{H}_{3} \mathrm{~N}\right)$ were purchased from Sinopharm Chemical Reagent Co. Ltd. (Shanghai, China); sodium hydroxide $(\mathrm{NaOH})$ and acetic acid glacial $\left(\mathrm{CH}_{3} \mathrm{COOH}\right)$ were purchased from Guangdong Guanghua Sci-Tech Co. Ltd. (Shantou, China). The water used in all the experiments was deionized water produced using the Millipore Milli Q system. All the reagents were used as received.

\subsubsection{Material synthesis}

2.1.2.1 Synthesis of $\mathrm{CeO}_{2}$ nanorods and nanocubes. $\mathrm{CeO}_{2}$ nanorods and nanocubes were prepared through a method similar to that reported in the literature. ${ }^{28}$ To obtain $\mathrm{CeO}_{2}$ nanorods, $1.736 \mathrm{~g}$ of $\mathrm{Ce}\left(\mathrm{NO}_{3}\right)_{3} \cdot 6 \mathrm{H}_{2} \mathrm{O}$ was dissolved in $10 \mathrm{~mL}$ of deionized water and stirred for $10 \mathrm{~min}$. In a separate container, $19.2 \mathrm{~g}$ of $\mathrm{NaOH}$ was dissolved in $70 \mathrm{~mL}$ of deionized water, and stirred until the solution turned into a transparent color. The above two solutions were mixed and stirred for $30 \mathrm{~min}$. Then, the mixed solution was transferred into a $100 \mathrm{~mL}$ Teflon-lined stainless autoclave and heated up to $100{ }^{\circ} \mathrm{C}$ for $24 \mathrm{~h}$. After the solution was cooled to room temperature, the precipitates were separated by filtration and washed with deionized water several times. The obtained precipitates were dried at $60{ }^{\circ} \mathrm{C}$ overnight, and then calcined at $400{ }^{\circ} \mathrm{C}$ for $4 \mathrm{~h}$. The procedure for the synthesis of $\mathrm{CeO}_{2}$ nanocubes was exactly the same as for $\mathrm{CeO}_{2}$ nanorods, except the hydrothermal condition was at $180{ }^{\circ} \mathrm{C}$ for $24 \mathrm{~h}$.

2.1.2.2 Synthesis of $\mathrm{MnO}_{x}-\mathrm{CeO}_{2}$ nanorods and nanocubes. $\mathrm{MnO}_{x}-\mathrm{CeO}_{2}$ nanorods and nanocubes were synthesized through a modified method reported in the literature. ${ }^{24,25}$ To obtain $\mathrm{MnO}_{x}-\mathrm{CeO}_{2}$ nanorods, $0.3957 \mathrm{~g}$ (50 mol\% of Mn with respect to Ce) of $\mathrm{MnCl}_{2} \cdot 4 \mathrm{H}_{2} \mathrm{O}$ and $0.868 \mathrm{~g}$ of $\mathrm{Ce}\left(\mathrm{NO}_{3}\right)_{3} \cdot 6 \mathrm{H}_{2} \mathrm{O}$ were dissolved into $5 \mathrm{~mL}$ and $10 \mathrm{~mL}$ of deionized water, respectively. Then the two solutions were mixed and stirred for $10 \mathrm{~min}$. In another container, $14 \mathrm{~g}$ of $\mathrm{NaOH}$ was dissolved into $35 \mathrm{~mL}$ of deionized water. Then, the $\mathrm{NaOH}$ solution was mixed with the metal precursor solution. After stirring for $30 \mathrm{~min}$, the slurry was transferred into a $100 \mathrm{~mL}$ Teflon-lined stainless autoclave and heated up to $120{ }^{\circ} \mathrm{C}$ for $24 \mathrm{~h}$. Upon leaving the solution to cool down to room temperature, the precipitates were separated by filtration and washed by deionized water several times. The precipitates were then dried at $60{ }^{\circ} \mathrm{C}$ overnight and calcined at $400{ }^{\circ} \mathrm{C}$ for $4 \mathrm{~h}$. $\mathrm{MnO}_{x}-\mathrm{CeO}_{2}$ nanocubes were synthesized using the same procedures as for the $\mathrm{MnO}_{x^{-}}$ $\mathrm{CeO}_{2}$ nanorods, except the hydrothermal condition was at $180{ }^{\circ} \mathrm{C}$ for $24 \mathrm{~h}$.

2.1.2.3 Synthesis of $\mathrm{MnO}_{2}$ catalysts. $\mathrm{MnO}_{2}$ catalysts were prepared by a modified method according to the literature reported by Zhu et al. ${ }^{29}$ In a typical experiment, $1.00 \mathrm{~g}$ of $\mathrm{KMnO}_{4}$ and $0.50 \mathrm{~g}$ of $50 \mathrm{wt} \% \mathrm{Mn}\left(\mathrm{NO}_{3}\right)_{2}$ solution were added into $64 \mathrm{~mL}$ of deionized water. After stirring for $10 \mathrm{~min}$, the mixed solution was transferred into a $100 \mathrm{~mL}$ Teflon-lined stainless autoclave and kept at $160{ }^{\circ} \mathrm{C}$ for $12 \mathrm{~h}$. After the solution was cooled to room temperature, the precipitates were washed and dried at $100{ }^{\circ} \mathrm{C}$ for $12 \mathrm{~h}$.

2.1.2.4 Synthesis of $\mathrm{Mn}_{3} \mathrm{O}_{4}$ catalysts. $\mathrm{Mn}_{3} \mathrm{O}_{4}$ catalysts were synthesized by adding $3.22 \mathrm{~g}$ of $50 \mathrm{wt} \% \mathrm{Mn}\left(\mathrm{NO}_{3}\right)_{2}$ solution and $1.78 \mathrm{~g}$ of $\mathrm{MnCl}_{2} \cdot 4 \mathrm{H}_{2} \mathrm{O}$ into $10 \mathrm{~mL}$ of deionized water. In another container, $100 \mathrm{~mL}$ of $3 \mathrm{M} \mathrm{NaOH}$ solution was prepared, and then mixed with the metal precursor solution. After stirring for $1 \mathrm{~h}$, the precipitates were washed using deionized water and dried at $100{ }^{\circ} \mathrm{C}$ for $12 \mathrm{~h}$.

\subsection{Catalyst characterization}

X-ray diffraction (XRD) patterns for the cerium-based catalysts were collected on a Rigaku X-ray diffractometer and $\mathrm{Cu} \mathrm{K} \alpha$ radiation ( $35 \mathrm{kV}$ and $20 \mathrm{~mA}$ ) was used as the X-ray source. The samples were scanned in the range of $10^{\circ}$ to $80^{\circ}$ at a scanning rate of $10^{\circ} \mathrm{min}^{-1}$. X-ray photoelectron spectra (XPS) were obtained from the PHI Quantum 2000 Scanning ESCA Microprobe and the monochromatic $\mathrm{Al} \mathrm{K} \alpha$ radiation $(1846.6 \mathrm{eV}$ ) was used as the X-ray source. The binding energies of all the spectra were calibrated with the reference to the $\mathrm{C} 1 \mathrm{~s}$ peak at $284.6 \mathrm{eV} \cdot \mathrm{N}_{2}$ adsorption-desorption isotherms were performed at $77 \mathrm{~K}$ using a Micromeritics ASAP 2020 instrument. All the samples (300 
$\mathrm{mg}$ ) were degassed at $200{ }^{\circ} \mathrm{C}$ for $2 \mathrm{~h}$ in vacuum before the measurements started. The specific surface areas were calculated by the Brunauer-Emmett-Teller (BET) method. Hydrogen temperature-programmed reduction $\left(\mathrm{H}_{2}\right.$-TPR) was recorded using a thermal conductivity detector (TCD). Typically, $80 \mathrm{mg}$ of sample was pretreated in pure argon (Ar) at $200{ }^{\circ} \mathrm{C}$ for $2 \mathrm{~h}$ with a flow rate of $40 \mathrm{~mL} \mathrm{~min}^{-1}$. After the temperature was cooled down to $50{ }^{\circ} \mathrm{C}$, the gas was switched to $5 \% \mathrm{H}_{2} / \mathrm{Ar}$ with a flow rate of $40 \mathrm{~mL} \mathrm{~min}{ }^{-1}$. The temperature was then raised to $850{ }^{\circ} \mathrm{C}$ at a ramp of $10{ }^{\circ} \mathrm{C} \mathrm{min}^{-1}$. Transmission electron microscopy (TEM) was performed on the Tecnai F30 with an acceleration voltage of $300 \mathrm{kV}$. The specimen was prepared by dispersing the sample in ethanol solution and sonicating for $20 \mathrm{~min}$. The dispersed sample was dripped on a carbon-coated copper grid and dried at room temperature. The catalyst composition was determined by inductively coupled plasma mass spectrometry (ICP-MS).

\subsection{Catalytic activity measurements}

The CWAO process was operated in a $100 \mathrm{~mL}$ temperatureprogrammed autoclave reactor with a magnetic-driven stirring mixer. A typical experiment was carried out as follows: $70 \mathrm{~mL}$ of phenol solution $(1000 \mathrm{ppm})$ and $0.28 \mathrm{~g}$ of catalyst $\left(4 \mathrm{~g} \mathrm{~L}^{-1}\right)$ were added into the reactor, and the reactor was purged using $\mathrm{N}_{2}$ to remove the gaseous oxygen. The reactor was allowed to heat to the required temperature $\left(100-180{ }^{\circ} \mathrm{C}\right)$ and the first sample was taken to evaluate the amount of phenol adsorbed. The desired amount of air (0.5-3.5 MPa) was then charged into the reactor, meanwhile, the time counting started. Samples were withdrawn periodically to monitor the progress of the reaction. The stirring speed was kept at 800 rotation per minute (rpm) at all times. The collected samples were filtered and the phenol concentrations were analyzed by Agilent 1100 high performance liquid chromatography (HPLC) instrument using a Dionex $\mathrm{C}_{18}$ column. The wavelength of the UV detector was set to $254 \mathrm{~nm}$. Acetonitrile and $0.2 \mathrm{wt} \%$ acetic acid solution were used as the mobile phases with a total flow rate of $1 \mathrm{~mL} \mathrm{~min}^{-1}$. The reaction evolutions of phenol's intermediates were also analyzed by HPLC according to the methods reported by Yang. ${ }^{9}$ Total organic carbon (TOC) was measured by a Shimadzu TOC-L analyzer.

\section{Results and discussion}

\subsection{Structural characterization}

The TEM images of $\mathrm{CeO}_{2}$ nanomaterials are displayed in Fig. 1 . The crystal size for $\mathrm{CeO}_{2}$ nanocubes and nanorods are 30 and $10 \mathrm{~nm}$ in diameter, respectively. The exposed surfaces for $\mathrm{CeO}_{2}$ nanorods are the (110) and (100) surfaces, rather than the (100) surface for $\mathrm{CeO}_{2}$ nanocubes. A clearer $\mathrm{CeO}_{2}$ nanorods (110) surface image is also provided in Fig. S1. $\dagger$ It is obvious that $\mathrm{CeO}_{2}$ nanorods have more "dark spots" and the surface seems "rougher" than that of the $\mathrm{CeO}_{2}$ nanocubes. A similar phenomenon was also reported by $\mathrm{Li}$, and it can be explained that the rougher surface of $\mathrm{CeO}_{2}$ nanorods is due to the formed oxygen vacancy clusters. ${ }^{19}$ Thus, it could be expected that $\mathrm{CeO}_{2}$ nanorods contain more oxygen vacancies than $\mathrm{CeO}_{2}$ nanocubes. The TEM results also indicate that the ceria (110) surface has a tendency to form more oxygen vacancies than the (100) surface, which is consistent with previous studies. ${ }^{\mathbf{2 0}, 21}$

The TEM images of $\mathrm{MnO}_{x}-\mathrm{CeO}_{2}$ nanocubes and nanorods are shown in Fig. 2. The average diameter of the $\mathrm{MnO}_{x}-\mathrm{CeO}_{2}$ nanocubes is about $17 \mathrm{~nm}$, and the exposed surface is confirmed to be the (100) surface, where the inter-planar space is $0.27 \mathrm{~nm}$. Fig. 2(c) and (d) are the typical images of $\mathrm{MnO}_{x^{-}}$ $\mathrm{CeO}_{2}$ nanorods, which have an average diameter of $10 \mathrm{~nm}$. The predominant facets for the $\mathrm{MnO}_{x}-\mathrm{CeO}_{2}$ nanorods are the (111) and (100) surfaces. The surface of $\mathrm{MnO}_{x}-\mathrm{CeO}_{2}$ nanorods was also found to be "rougher" than the surface of $\mathrm{MnO}_{x}-\mathrm{CeO}_{2}$ nanocubes, which implies that $\mathrm{MnO}_{x}-\mathrm{CeO}_{2}$ nanorods have more surface reconstructions and oxygen vacancies. The existence of oxygen vacancy clusters can promote the transition from $\mathrm{Ce}^{4+}$ to $\mathrm{Ce}^{3+}$, which generates more active oxygen species. ${ }^{30}$ This property of $\mathrm{CeO}_{2}$ and $\mathrm{MnO}_{x}-\mathrm{CeO}_{2}$ nanorods is expected to play an important role in the CWAO of phenol.

In order to confirm the chemical compositions of the $\mathrm{MnO}_{x^{-}}$ $\mathrm{CeO}_{2}$ catalysts, line-scan analysis was conducted (Fig. 3). For both $\mathrm{MnO}_{x}-\mathrm{CeO}_{2}$ nanocubes and nanorods, $\mathrm{Mn}$ and Ce follow the same pattern, which suggests that they may have formed solid solutions. ICP-MS analysis was performed to further verify the elemental compositions of the $\mathrm{MnO}_{x}-\mathrm{CeO}_{2}$ nanocubes and nanorods. The results show that both $\mathrm{MnO}_{x}-\mathrm{CeO}_{2}$ nanocubes and nanorods contain $48 \mathrm{~mol} \%$ of $\mathrm{Mn}$. Therefore, it was proven that $\mathrm{MnO}_{x}-\mathrm{CeO}_{2}$ nanocubes and nanorods have similar chemical compositions.

The XRD patterns of $\mathrm{CeO}_{2}$ and the $\mathrm{MnO}_{x}-\mathrm{CeO}_{2}$ nanomaterials are presented in Fig. 4. All the catalysts have the fluorite cubic structures of $\mathrm{CeO}_{2}$ (PDF \# 34-0394), in spite of there being some minor peaks of $\mathrm{Mn}_{3} \mathrm{O}_{4}$ (PDF \# 18-0803) found for the $\mathrm{MnO}_{x}-\mathrm{CeO}_{2}$ nanocubes. This indicates that less $\mathrm{Mn}$ has doped into the ceria lattice for $\mathrm{MnO}_{x}-\mathrm{CeO}_{2}$ nanocubes. To clarify this phenomenon, magnified (111) diffraction peaks of $\mathrm{MnO}_{x}-\mathrm{CeO}_{2}$ nanomaterials with reference to $\mathrm{CeO}_{2}$ nanorods are illustrated in Fig. 5.

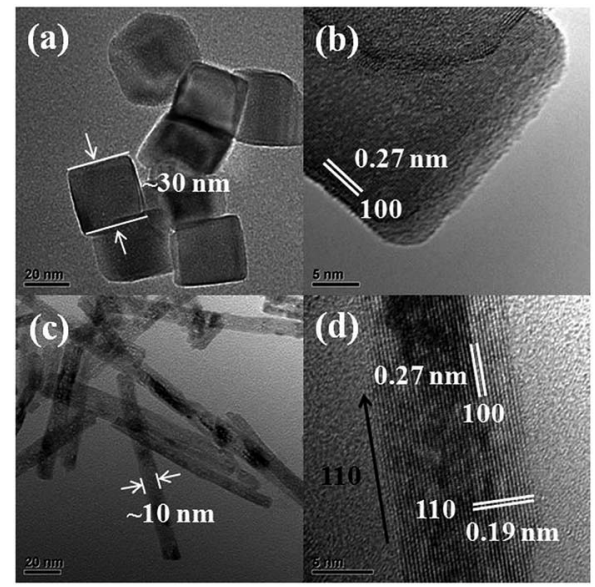

Fig. 1 TEM images of the $\mathrm{CeO}_{2}$ nanocubes ( $\mathrm{a}$ and $\mathrm{b}$ ) and nanorods ( $\mathrm{c}$ and d). 


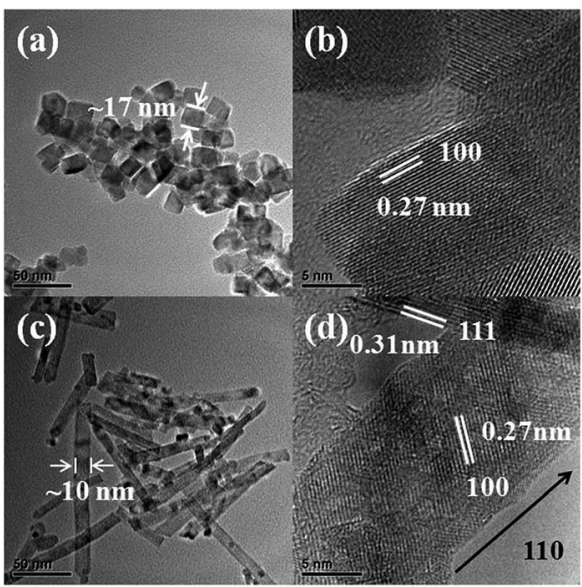

Fig. 2 TEM images of the $\mathrm{MnO}_{x}-\mathrm{CeO}_{2}$ nanocubes ( $a$ and b) and nanorods (c and d).
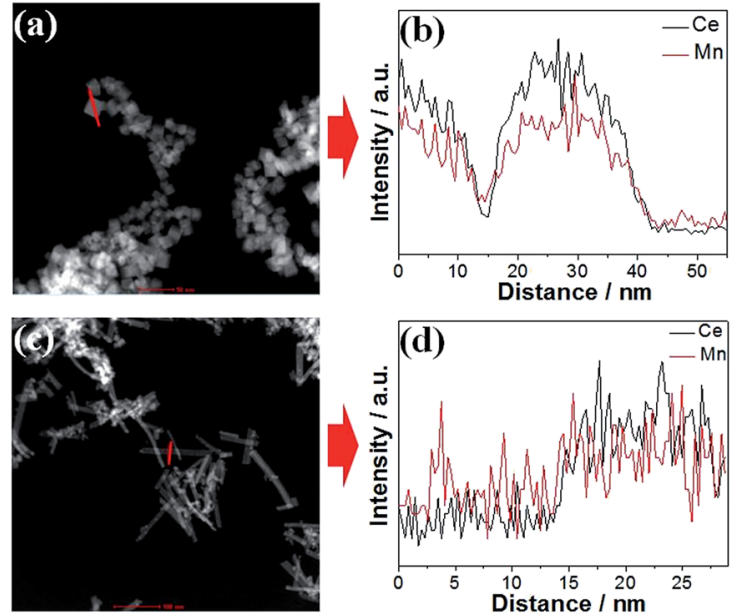

Fig. 3 Line-scan analyses of the $\mathrm{MnO}_{x}-\mathrm{CeO}_{2}$ nanocubes ( $a$ and $b$ ) and nanorods (c and d).

It was found that the diffraction peak for $\mathrm{MnO}_{x}-\mathrm{CeO}_{2}$ nanorods had shifted to a higher Bragg angle compared with $\mathrm{MnO}_{x}-\mathrm{CeO}_{2}$ nanocubes. The Bragg diffraction of each (111) peak was recorded, and each corresponding lattice parameter a was calculated (Fig. 5(b)). Indeed, the lattice parameter of the $\mathrm{MnO}_{x}-\mathrm{CeO}_{2}$ nanorods shrunk from $0.541 \mathrm{~nm}$ to $0.537 \mathrm{~nm}$, whereas $\mathrm{MnO}_{x}-\mathrm{CeO}_{2}$ nanocubes only decreased to $0.539 \mathrm{~nm}$. This further justifies that $\mathrm{MnO}_{x}-\mathrm{CeO}_{2}$ nanorods have formed a more homogeneous solid solution. Furthermore, the ionic radii of $\mathrm{Mn}$ ions were reported as follows: $\mathrm{Mn}^{4+}: 0.053 \mathrm{~nm}$, $\mathrm{Mn}^{3+}: 0.065 \mathrm{~nm}, \mathrm{Mn}^{2+}: 0.083 \mathrm{~nm} .{ }^{26}$ The ionic radii of cerium ions were: $\mathrm{Ce}^{4+}: 0.097 \mathrm{~nm}, \mathrm{Ce}^{3+}: 0.114 \mathrm{~nm}$. Thus, if more $\mathrm{Mn}$ is doped into Ce for the $\mathrm{MnO}_{x}-\mathrm{CeO}_{2}$ nanorods, the average ionic radius is expected to be smaller than that of $\mathrm{MnO}_{x}-\mathrm{CeO}_{2}$ nanocubes, which might cause a decrease in the lattice parameters.

Moreover, Fig. 4 also illustrates that $\mathrm{CeO}_{2}$ and $\mathrm{MnO}_{x}-\mathrm{CeO}_{2}$ nanocubes have greater intensity than the corresponding
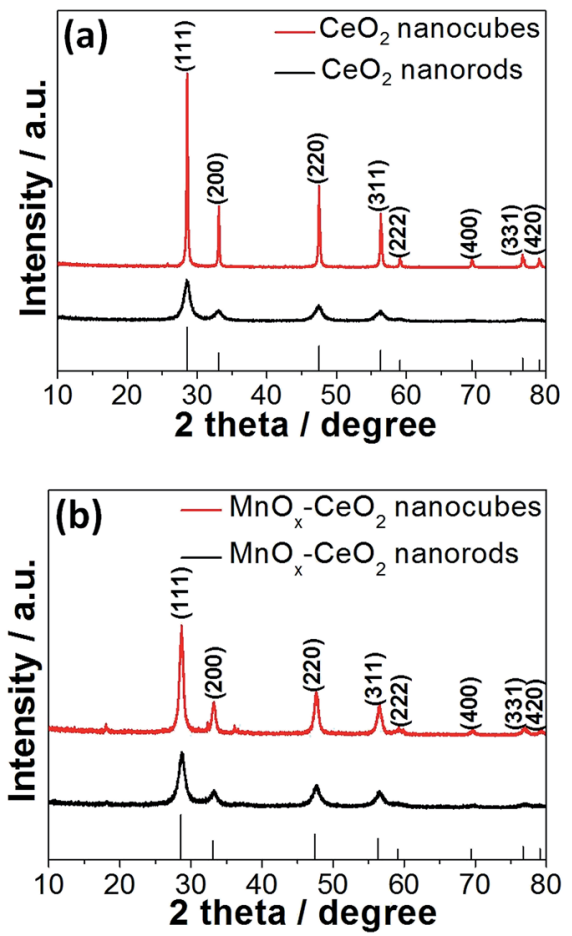

Fig. 4 XRD patterns of the $\mathrm{CeO}_{2}$ (a) and $\mathrm{MnO}_{x}-\mathrm{CeO}_{2}$ (b) nanomaterials.

nanorods. This reveals that $\mathrm{CeO}_{2}$ and $\mathrm{MnO}_{x}-\mathrm{CeO}_{2}$ nanorods have a higher degree of lattice defects than the corresponding cubic morphology. ${ }^{8,28}$ This is consistent with the TEM results discussed earlier. The diffraction peaks of $\mathrm{CeO}_{2}$ and $\mathrm{MnO}_{x^{-}}$ $\mathrm{CeO}_{2}$ nanorods are also relatively broader compared to the $\mathrm{CeO}_{2}$ and $\mathrm{MnO}_{x}-\mathrm{CeO}_{2}$ nanocubes, suggesting that $\mathrm{CeO}_{2}$ and $\mathrm{MnO}_{x}-$ $\mathrm{CeO}_{2}$ nanorods have a smaller crystal size and would result in a higher specific surface area. This was further confirmed by the BET measurements, which show that the BET areas of $\mathrm{CeO}_{2}$ and $\mathrm{MnO}_{x}-\mathrm{CeO}_{2}$ nanorods were 91.5 and $76.7 \mathrm{~m}^{2} \mathrm{~g}^{-1}$, respectively. The BET areas of $\mathrm{CeO}_{2}$ and $\mathrm{MnO}_{x}-\mathrm{CeO}_{2}$ nanocubes were 15.4 and $39.2 \mathrm{~m}^{2} \mathrm{~g}^{-1}$, respectively. From the data shown above, it is apparent that the specific surface area was affected by the catalyst particle size. Generally, the smaller the particle size is, the larger BET surface area the catalyst possesses. As shown in Fig. 1 and 2, the particle size is increased in the following order: $\mathrm{CeO}_{2}$ nanorods $(10 \mathrm{~nm}) \approx \mathrm{MnO}_{x}-\mathrm{CeO}_{2}$ nanorods $(10 \mathrm{~nm})<$ $\mathrm{MnO}_{x}-\mathrm{CeO}_{2}$ nanocubes $(17 \mathrm{~nm})<\mathrm{CeO}_{2}$ nanocubes $(30 \mathrm{~nm})$. Therefore, the specific surface area is negatively related to the particle size: $\mathrm{CeO}_{2}$ nanorods $\left(91.5 \mathrm{~m}^{2} \mathrm{~g}^{-1}\right)>\mathrm{MnO}_{x}-\mathrm{CeO}_{2}$ nanorods $\left(76.7 \mathrm{~m}^{2} \mathrm{~g}^{-1}\right)>\mathrm{MnO}_{x}-\mathrm{CeO}_{2}$ nanocubes $\left(39.2 \mathrm{~m}^{2} \mathrm{~g}^{-1}\right)>$ $\mathrm{CeO}_{2}$ nanocubes $\left(15.4 \mathrm{~m}^{2} \mathrm{~g}^{-1}\right)$. Furthermore, as shown in Fig. 4, $\mathrm{CeO}_{2}$ nanorods exhibited weaker XRD patterns than $\mathrm{MnO}_{x}-$ $\mathrm{CeO}_{2}$ nanorods. This indicated that $\mathrm{CeO}_{2}$ nanorods possessed poorer crystallinity and a smaller crystal size, although similar diameters were observed by TEM over the two catalysts. The poorer crystallinity and smaller crystal size enabled $\mathrm{CeO}_{2}$ nanorods to have a larger BET surface area than $\mathrm{MnO}_{x}-\mathrm{CeO}_{2}$ nanorods. 

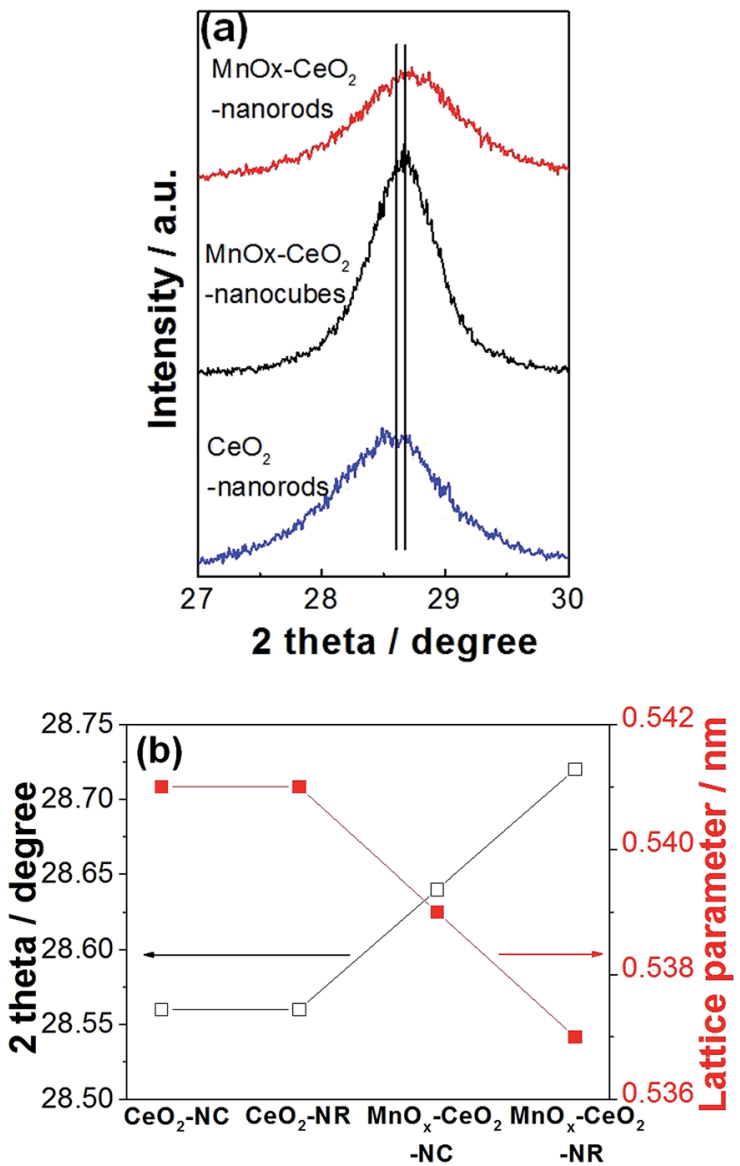

Fig. 5 Magnified (111) diffraction peaks (a) and the effect of Mn doping on cerium lattice parameters (b).

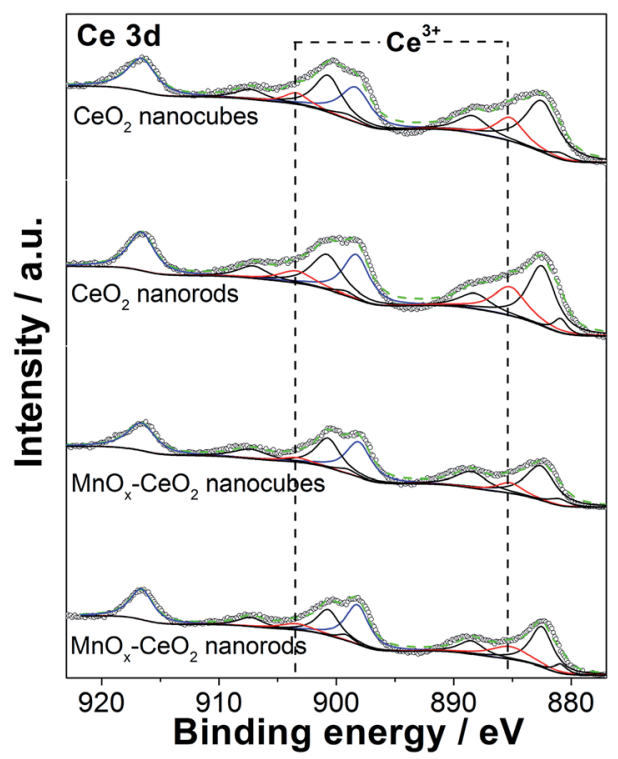

Fig. $6 \mathrm{Ce} 3 \mathrm{~d}$ core level XPS spectra of the $\mathrm{CeO}_{2}$ and $\mathrm{MnO}_{x}-\mathrm{CeO}_{2}$ catalysts.

\subsection{Valence state and redox properties}

The XPS spectrum of Ce 3d is displayed in Fig. 6. Typically, 10 peaks were deconvoluted into pairs of spin orbit doublets. Two peaks at 916.6 and $898.2 \mathrm{eV}$ are attributed to the $3 \mathrm{~d}_{3 / 2}$, which correspond to the $\mathrm{Ce}^{4+}$ states. Two peaks at 903.4 and $885.2 \mathrm{eV}$ are assigned to the $3 \mathrm{~d}_{5 / 2}$, which are the $\mathrm{Ce}^{3+}$ states. The other six peaks at $900.7,882.5,907.3,888.5,899.2$, and $880.9 \mathrm{eV}$ are the satellite peaks due to the "shake down" type processes. ${ }^{31}$ These results agree with what we found in the literature..$^{32}$ The relative portion of $\mathrm{Ce}^{3+}$ and $\mathrm{Ce}^{4+}$ valence states are summarized in Table 1. It was found that $\mathrm{CeO}_{2}$ nanorods have $6 \%$ more $\mathrm{Ce}^{3+}$ ions than $\mathrm{CeO}_{2}$ nanocubes, whereas $\mathrm{MnO}_{x}-\mathrm{CeO}_{2}$ nanorods contain $11 \%$ more $\mathrm{Ce}^{3+}$ ions than $\mathrm{MnO}_{x}-\mathrm{CeO}_{2}$ nanocubes. The oxygen vacancy concentration is positively related to the concentration of $\mathrm{Ce}^{3+}$ ions, because oxygen vacancies can reduce the thermodynamic barrier for the transition from $\mathrm{Ce}^{4+}$ to $\mathrm{Ce}^{3+} \cdot{ }^{30}$ Thus, the XPS results are consistent with the XRD and TEM results, which helps to explain why $\mathrm{CeO}_{2}$ and $\mathrm{MnO}_{x}-\mathrm{CeO}_{2}$ nanorods have rougher surfaces.

The Mn 2p spectra of the $\mathrm{MnO}_{x}-\mathrm{CeO}_{2}$ catalysts are shown in Fig. 7. The three peaks of $\mathrm{Mn} 2 \mathrm{p}_{3 / 2}$ are located at 640.8, 641.8, and $643.9 \mathrm{eV}$, corresponding to $\mathrm{Mn}^{2+}, \mathrm{Mn}^{3+}$, and $\mathrm{Mn}^{4+}$, respectively. ${ }^{33-35}$ The Mn $2 \mathrm{p}_{1 / 2}$ peak is centered at $653.3 \mathrm{eV}$, with a splitting energy of 11.45 , based on the $\mathrm{Mn} 2 \mathrm{p}_{3 / 2}$. By estimating the area of each $\mathrm{Mn}$ species, Table 1 shows that $\mathrm{MnO}_{x}-\mathrm{CeO}_{2}$ nanorods contain a larger portion of higher valence $\mathrm{Mn}$ species, whereas the corresponding $\mathrm{Mn}^{4+}, \mathrm{Mn}^{3+}$, and $\mathrm{Mn}^{2+}$ ion abundances are $23 \%, 62 \%$, and $15 \%$, respectively. Conversely, $\mathrm{MnO}_{x}-\mathrm{CeO}_{2}$ nanocubes prefer lower valence $\mathrm{Mn}$ species, and the corresponding portions of $\mathrm{Mn}^{4+}, \mathrm{Mn}^{3+}$, and $\mathrm{Mn}^{2+}$ are $14 \%$, $36 \%$, and $50 \%$, respectively.

It was also found that the $\mathrm{Ce}^{3+}$ concentration was suppressed when Mn was added. This effect was also reported by Larachi, where the addition of $\mathrm{Mn}$ caused an increase in surface $\mathrm{Ce}^{4+}$ concentration. ${ }^{36}$ This phenomenon can be explained by the fact that electrons are transferred from $\mathrm{Ce}$ to $\mathrm{Mn}$, which can decrease the concentration of $\mathrm{Ce}^{3+}$ and increase the concentration of $\mathrm{Mn}^{2+}$ or $\mathrm{Mn}^{3+}$. Compared to $\mathrm{MnO}_{x}-\mathrm{CeO}_{2}$ nanorods, the $\mathrm{Ce}^{3+}$ concentration of $\mathrm{MnO}_{x}-\mathrm{CeO}_{2}$ nanocubes was suppressed to a higher extent, and a much greater fraction of $\mathrm{Mn}^{2+}$ was observed. This also suggests that more electrons are transferred from Ce to $\mathrm{Mn}$ for $\mathrm{MnO}_{x}-\mathrm{CeO}_{2}$ nanocubes.

Noted that the $\mathrm{Mn}^{3+} / \mathrm{Mn}^{2+}$ that are incorporated into the $\mathrm{CeO}_{2}$ lattice sites also contribute to the oxygen vacancies formation. $\mathrm{MnO}_{x}-\mathrm{CeO}_{2}$ nanocubes contained more $\mathrm{Mn}^{2+}$ species, but showed lower oxygen vacancies concentration than $\mathrm{MnO}_{x}-\mathrm{CeO}_{2}$ nanorods. Two possible reasons were responsible for the lower concentration of oxygen vacancies over $\mathrm{MnO}_{x^{-}}$ $\mathrm{CeO}_{2}$ nanocubes. First, some part of the $\mathrm{Mn}$ was not incorporated into the $\mathrm{CeO}_{2}$ lattice for the $\mathrm{MnO}_{x}-\mathrm{CeO}_{2}$ nanocubes. $\mathrm{Mn}_{3} \mathrm{O}_{4}$ was detected by XRD, as shown in Fig. 4(b). It is well known that $\mathrm{Mn}_{3} \mathrm{O}_{4}$ is composed of both $\mathrm{Mn}^{3+}$ and $\mathrm{Mn}^{2+} \cdot 37,38$ Some $\mathrm{Mn}^{3+} / \mathrm{Mn}^{2+}$ species come from the phase-segregated $\mathrm{Mn}_{3} \mathrm{O}_{4}$. These lower valence $\mathrm{Mn}$ species must not contribute to the formation of oxygen vacancies, since they were not in the $\mathrm{CeO}_{2}$ lattice. Second, when $\mathrm{Mn}$ is doped into $\mathrm{CeO}_{2}$, electrons 
Table 1 Relative abundance of the different species obtained from the XPS data for each catalyst

\begin{tabular}{|c|c|c|c|c|c|}
\hline Catalyst label & $\mathrm{Ce}^{3+}(\%)$ & $\mathrm{Mn}^{4+}(\%)$ & $\mathrm{Mn}^{3+}(\%)$ & $\mathrm{Mn}^{2+}(\%)$ & $\mathrm{O}_{\text {active }}(\%)$ \\
\hline $\mathrm{CeO}_{2}$ nanocubes & 32 & - & - & - & 16 \\
\hline $\mathrm{CeO}_{2}$ nanorods & 38 & - & - & - & 20 \\
\hline $\mathrm{MnCeO}_{x}$ nanorods & 30 & 23 & 62 & 15 & 26 \\
\hline
\end{tabular}

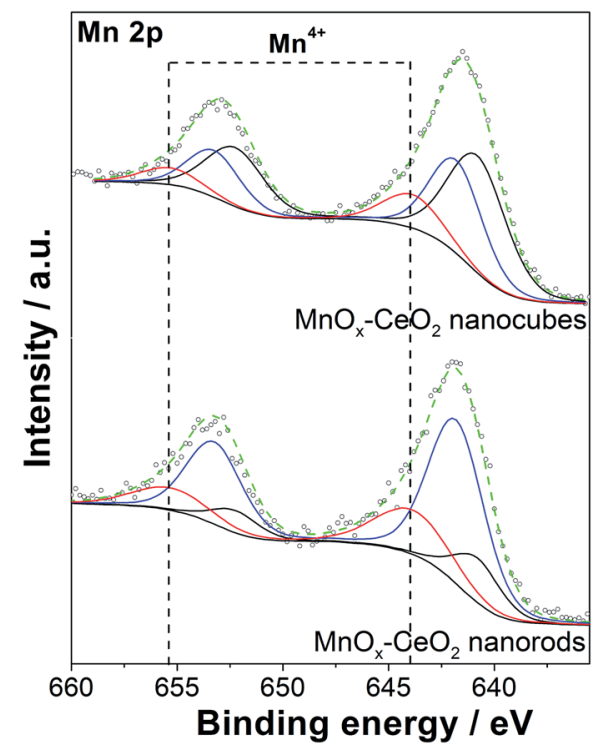

Fig. $7 \mathrm{Mn} 2 \mathrm{p}$ core level XPS spectra of the $\mathrm{MnO}_{x}-\mathrm{CeO}_{2}$ catalysts.

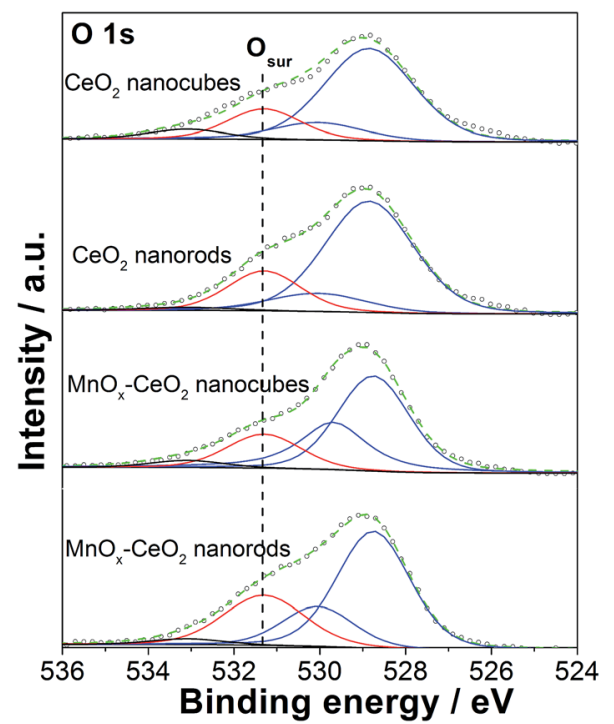

Fig. $8 \mathrm{O}$ 1s core level XPS spectra of the $\mathrm{CeO}_{2}$ and $\mathrm{MnO}_{x}-\mathrm{CeO}_{2}$ catalysts.

were transferred from $\mathrm{Ce}$ to $\mathrm{Mn}$ and the $\mathrm{Ce}^{3+}$ fraction was decreased from $32 \%$ to $19 \%$. Some oxygen vacancies over $\mathrm{Mn}^{3+}$ / $\mathrm{Mn}^{2+}$ were produced at the expense of those over $\mathrm{Ce}^{3+}$ sites. Therefore, although a higher concentration of low valence Mn
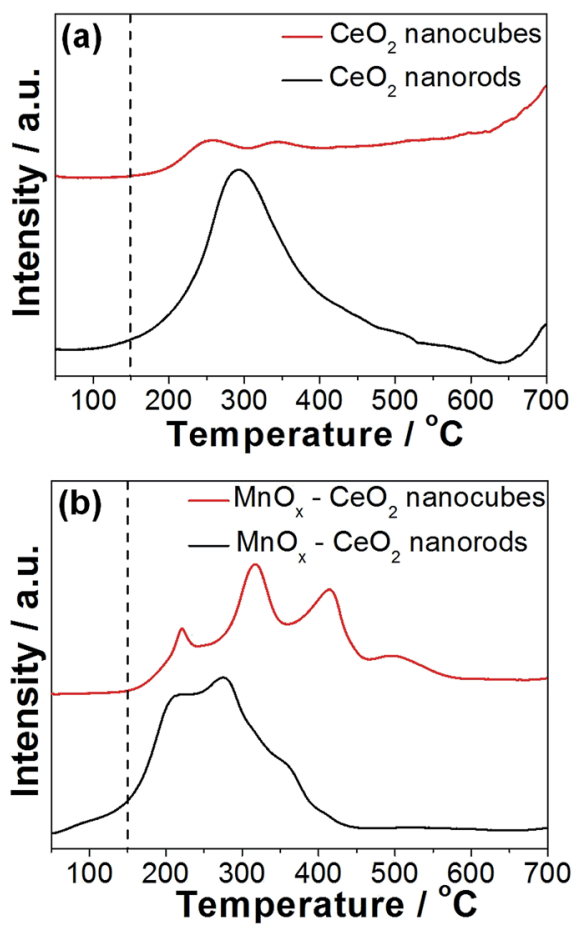

Fig. $9 \mathrm{H}_{2}$-TPR results of the $\mathrm{CeO}_{2}$ (a) and $\mathrm{MnO}_{x}-\mathrm{CeO}_{2}$ (b) catalysts.

Table 2 Summary of the catalytic activity of different metal oxides on the CWAO of phenol. Phenol concentration: 1000 ppm; catalyst loading: $4 \mathrm{~g} \mathrm{~L}^{-1}$; temperature: $140{ }^{\circ} \mathrm{C}$; pressure: $2 \mathrm{MPa}$ air; time: $1 \mathrm{~h}$

\begin{tabular}{lll}
\hline Catalyst label & $\begin{array}{l}\text { Phenol conversion } \\
(\%)\end{array}$ & $\begin{array}{l}\text { TOC conversion } \\
(\%)\end{array}$ \\
\hline $\mathrm{CeO}_{2}$ nanocubes & 8 & 6 \\
$\mathrm{CeO}_{2}$ nanorods & 27 & 23 \\
$\mathrm{MnO}_{2}$ & 79 & 67 \\
$\mathrm{Mn}_{3} \mathrm{O}_{4}$ & 70 & 62 \\
$\mathrm{MnCeO}_{x}$ nanocubes & 100 & 97 \\
$\mathrm{MnCeO}_{x}$ nanorods & 100 & 98
\end{tabular}

species was detected by XPS, the $\mathrm{MnO}_{x}-\mathrm{CeO}_{2}$ nanocubes still exhibited a lower concentration of oxygen vacancies. In the case of $\mathrm{MnO}_{x}-\mathrm{CeO}_{2}$ nanorods, electron transfer between $\mathrm{Mn}$ and Ce was also observed. However, the electron transfer was less significant than that over $\mathrm{MnO}_{x}-\mathrm{CeO}_{2}$ nanocubes. After the addition of $\mathrm{Mn}$, the $\mathrm{Ce}^{3+}$ fraction was still up to $30 \%$. Additionally, most of $\mathrm{Mn}$ was incorporated into the $\mathrm{CeO}_{2}$ lattice for the $\mathrm{MnO}_{x}-\mathrm{CeO}_{2}$ nanorods, as proved by the XRD results. Thus, 

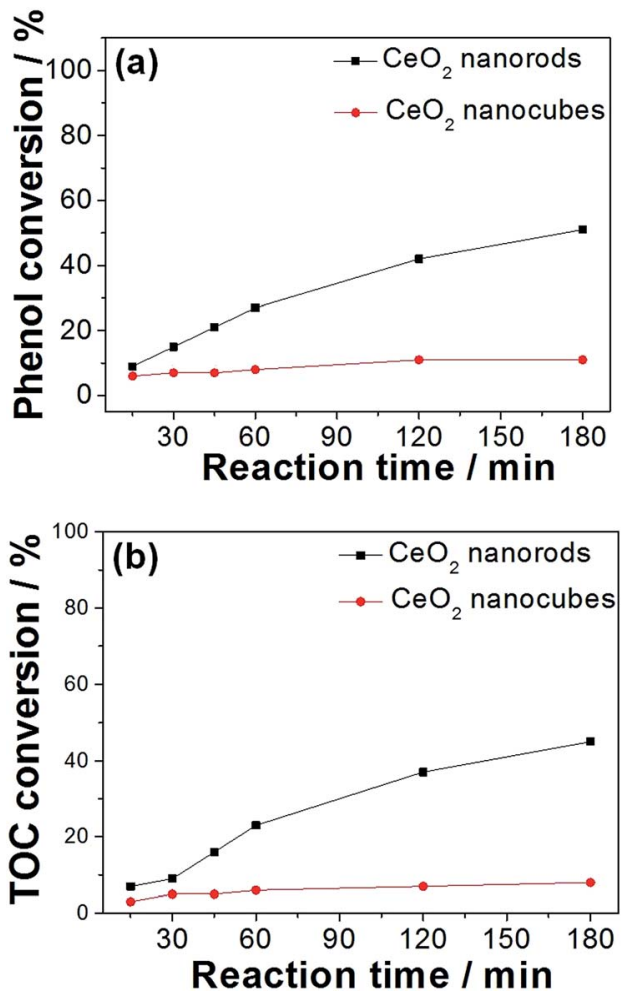

Fig. 10 The CWAO of phenol using $\mathrm{CeO}_{2}$ nanorods and nanocubes, (a) phenol conversion, (b) TOC conversion. Concentration of phenol: 1000 ppm; catalyst loading: $4 \mathrm{~g} \mathrm{~L}^{-1}$; temperature: $140{ }^{\circ} \mathrm{C}$; pressure: $2 \mathrm{MPa}$ air

$\mathrm{Mn}^{3+} / \mathrm{Mn}^{2+}$ might have contributed to the formation of oxygen vacancies for the $\mathrm{MnO}_{x}-\mathrm{CeO}_{2}$ nanorods.

Fig. 8 shows the $\mathrm{O} 1$ s spectra for the $\mathrm{CeO}_{2}$ and $\mathrm{MnO}_{x}-\mathrm{CeO}_{2}$ nanomaterials. The peaks appearing at 528.9 and $530 \mathrm{eV}$ are the lattice oxygen of the $\mathrm{CeO}_{2}$ and $\mathrm{MnO}_{x}-\mathrm{CeO}_{2}$ catalysts. ${ }^{39}$ The peak at $531.4 \mathrm{eV}$ is the adsorbed active oxygen species, the peroxo species $\left(\mathrm{O}_{2}{ }^{2-}\right)$, and the superoxo species $\left(\mathrm{O}_{2}{ }^{-}\right) \cdot{ }^{40}$ The remaining peak at $533 \mathrm{eV}$ is attributed to the adsorbed surface hydroxyl and water species. For the $\mathrm{CeO}_{2}$ catalysts, $\mathrm{CeO}_{2}$ nanorods possess $20 \%$ surface active oxygen, where $\mathrm{CeO}_{2}$ nanocubes have $16 \%$. It is reported that oxygen vacancies can promote the formation of $\mathrm{Ce}^{3+}$, and that $\mathrm{Ce}^{3+}$ can induce the formation of active oxygen species. ${ }^{41}$ Thus, the cause of the higher active oxygen percentage for $\mathrm{CeO}_{2}$ nanorods might be due to the oxygen vacancies formed on the $\mathrm{CeO}_{2}$ nanorods surface. A similar trend was also observed for the $\mathrm{MnO}_{x}-\mathrm{CeO}_{2}$ catalysts, where $\mathrm{MnO}_{x}-\mathrm{CeO}_{2}$ nanorods contained $8 \%$ more active surface oxygen than $\mathrm{MnO}_{x}-\mathrm{CeO}_{2}$ nanocubes. It is also reported that active oxygen species can be created at the interface between the $\mathrm{CeO}_{2}$ lattice and $\mathrm{MnO}_{x}{ }^{26}$ It is reasonable that more active oxygen species are found in $\mathrm{MnO}_{x}-\mathrm{CeO}_{2}$ nanorods, due to the synergy of $\mathrm{Mn} / \mathrm{Ce}$ (more-MnO-Ce- bonds) and the higher $\mathrm{Ce}^{3+}$ concentration.

The redox properties of the $\mathrm{CeO}_{2}$ and $\mathrm{MnO}_{x}-\mathrm{CeO}_{2}$ catalysts were studied by $\mathrm{H}_{2}$-TPR experiments, and the results are displayed in Fig. 9. It is widely accepted that the low temperature
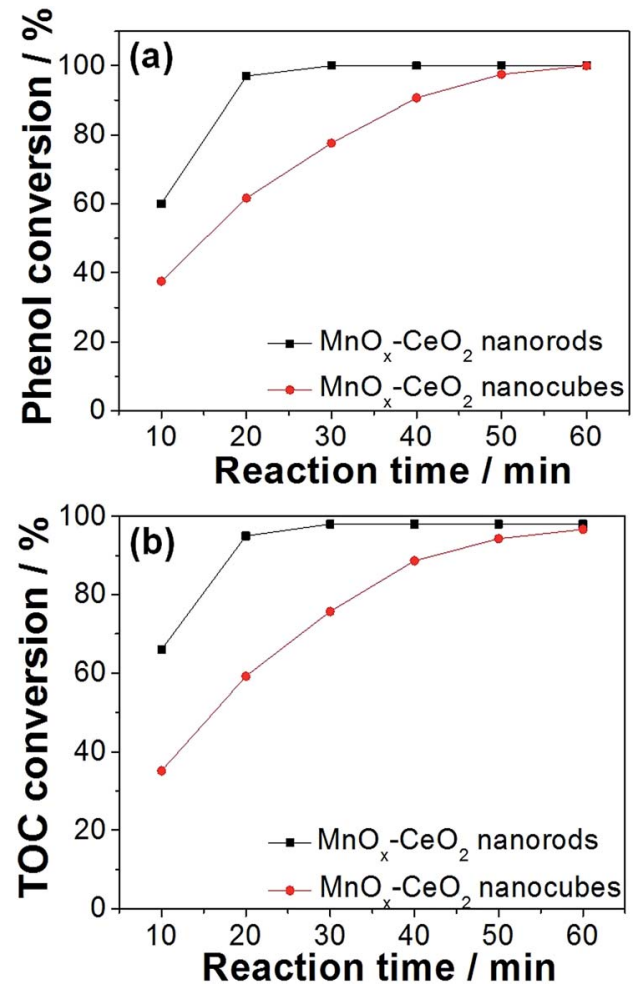

Fig. 11 Phenol (a) and TOC (b) conversions on $\mathrm{MnO}_{x}-\mathrm{CeO}_{2}$ nanorods and nanocubes. Concentration of phenol: 1000 ppm; catalyst loading: $4 \mathrm{~g} \mathrm{~L}^{-1}$; temperature: $140{ }^{\circ} \mathrm{C}$; pressure: $2 \mathrm{MPa}$ air.

reduction peak of $\mathrm{CeO}_{2}$ nanomaterials relates to the removal of surface capping oxygens, while the high temperature reduction peak is related to the bulk oxygen..$^{42,43}$ It was observed that $\mathrm{CeO}_{2}$ nanorods are able to remove surface oxygen at $100{ }^{\circ} \mathrm{C}$, while $\mathrm{CeO}_{2}$ nanocubes start to reduce at $150{ }^{\circ} \mathrm{C}$. This indicates that $\mathrm{CeO}_{2}$ nanorods have more reducible surface $\mathrm{Ce}^{4+}$ ions compared with that of $\mathrm{CeO}_{2}$ nanocubes, which is attributed to the oxygen vacancies formed on the $\mathrm{CeO}_{2}$ nanorods surface, because oxygen vacancies can boost the transition from $\mathrm{Ce}^{4+}$ to $\mathrm{Ce}^{3+}$.

Doping $\mathrm{Mn}$ into the Ce lattice can improve the reducibility of the catalyst surface, ${ }^{27}$ which can clearly be observed in Fig. 9(b). The reduction peak of $\mathrm{MnO}_{x}-\mathrm{CeO}_{2}$ nanorods starts at $50{ }^{\circ} \mathrm{C}$, while $\mathrm{MnO}_{x}-\mathrm{CeO}_{2}$ nanocubes start to reduce at $150{ }^{\circ} \mathrm{C}$. Four reduction peaks were obtained for each $\mathrm{MnO}_{x}-\mathrm{CeO}_{2}$ catalyst. For $\mathrm{MnO}_{x}-\mathrm{CeO}_{2}$ nanorods, the peak at $200{ }^{\circ} \mathrm{C}$ is attributed to the reduction of $\mathrm{MnO}_{2}$ to $\mathrm{Mn}_{2} \mathrm{O}_{3}$. The second peak at $272{ }^{\circ} \mathrm{C}$ is assigned to the reduction of $\mathrm{Mn}_{2} \mathrm{O}_{3}$ to $\mathrm{Mn}_{3} \mathrm{O}_{4}$. The third peak at $360{ }^{\circ} \mathrm{C}$ is the mixed reduction of $\mathrm{Mn}_{3} \mathrm{O}_{4}$ to $\mathrm{MnO}$ and surface $\mathrm{Ce}^{4+}$ to $\mathrm{Ce}^{3+}$, while the high temperature reduction peak at $410{ }^{\circ} \mathrm{C}$ is the reduction of the bulk $\mathrm{Ce}^{4+}$ to $\mathrm{Ce}^{3+} .{ }^{35,44}$

The reduction peaks for $\mathrm{MnO}_{x}-\mathrm{CeO}_{2}$ nanocubes followed a similar pattern as that of the $\mathrm{MnO}_{x}-\mathrm{CeO}_{2}$ nanorods. It was found that $\mathrm{MnO}_{2}$ was first reduced to $\mathrm{Mn}_{2} \mathrm{O}_{3}$ at $220^{\circ} \mathrm{C}$, and then $\mathrm{Mn}_{2} \mathrm{O}_{3}$ was reduced to $\mathrm{Mn}_{3} \mathrm{O}_{4}$ at $315{ }^{\circ} \mathrm{C}$. The third peak at $415{ }^{\circ} \mathrm{C}$ is due to the reduction of $\mathrm{Mn}_{3} \mathrm{O}_{4}$ to $\mathrm{MnO}$. The reduction of surface $\mathrm{Ce}^{4+}$ was shifted to a high temperature around $500{ }^{\circ} \mathrm{C}$ 

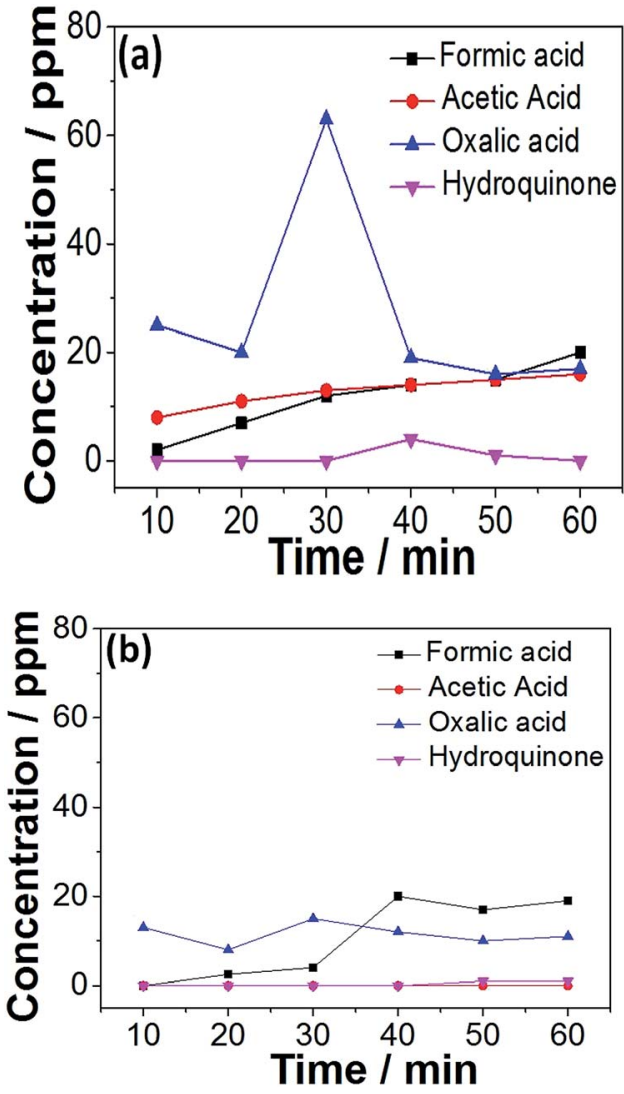

Fig. 12 Evolution of the small-molecule intermediates in the CWAO of phenol over $\mathrm{MnO}_{x}-\mathrm{CeO}_{2}$ nanorods (a) and nanocubes (b).

due to the lower concentration of $\mathrm{Ce}^{3+}$ and the electron transfer from Ce to $\mathrm{Mn}$. Compared to the reduction peaks of $\mathrm{MnO}_{x^{-}}$ $\mathrm{CeO}_{2}$ nanorods, all of the reduction peaks for $\mathrm{MnO}_{x}-\mathrm{CeO}_{2}$ nanocubes have shifted to higher temperatures. This is reasonable since more $\mathrm{Mn}$ has entered the Ce lattice for $\mathrm{MnO}_{x}-$ $\mathrm{CeO}_{2}$ nanorods, which causes the formation of $-\mathrm{Mn}-\mathrm{O}-\mathrm{Ce}-$ bonds. It was reported that $-\mathrm{Mn}-\mathrm{O}-\mathrm{Ce}-$ bonds is more reducible than $-\mathrm{Ce}-\mathrm{O}-$ or $-\mathrm{Mn}-\mathrm{O}-$ bonds. ${ }^{26}$ The presence of $-\mathrm{Mn}-\mathrm{O}-$ $\mathrm{Ce}-$ bonds effectively lowered the overall reduction temperature for $\mathrm{MnO}_{x}-\mathrm{CeO}_{2}$ nanorods.

It is interesting that $\mathrm{MnO}_{x}-\mathrm{CeO}_{2}$ nanorods also possess more compacted reduction peaks than $\mathrm{MnO}_{x}-\mathrm{CeO}_{2}$ nanocubes. This might be due to the greater abundance of $\mathrm{Mn}^{4+}$ and $\mathrm{Mn}^{3+}$ of $\mathrm{MnO}_{x}-\mathrm{CeO}_{2}$ nanorods, because higher oxidation states of $\mathrm{Mn}$ are easier to be reduced. Another possible explanation is that oxygen vacancies in $\mathrm{MnO}_{x}-\mathrm{CeO}_{2}$ nanorods could also promote the transition of $\mathrm{Mn}$ from $4+$ to lower valence states, since it is able to lower the thermodynamic barrier for $\mathrm{Ce}^{4+} \rightarrow \mathrm{Ce}^{3+}$.

\subsection{Catalytic wet air oxidation of phenol}

The catalytic performance of various oxides were investigated and the results are displayed in Table 2. It was found that cerium and manganese monoxides (Fig. S2 $\dagger$ ) exhibit much lower activities for the CWAO of phenol than the $\mathrm{MnO}_{x}-\mathrm{CeO}_{2}$ catalysts, which proves the effectiveness of $\mathrm{Mn} / \mathrm{Ce}$ oxide composites. In order to study the effect of oxygen vacancies on the CWAO of phenol, $\mathrm{CeO}_{2}$ nanorods and nanocubes were carefully investigated. The adsorption experiments showed that $\mathrm{CeO}_{2}$ nanorods could absorb 5\% of phenol, whereas $\mathrm{CeO}_{2}$ nanocubes could only absorb $1 \%$. Fig. 10 illustrates the reaction profiles of phenol and TOC conversions for $\mathrm{CeO}_{2}$ nanomaterials at $140{ }^{\circ} \mathrm{C}$ and $2 \mathrm{MPa}$ air. It was found that $\mathrm{CeO}_{2}$ nanocubes were almost inert toward the CWAO of phenol, whereas phenol and total organic carbon (TOC) conversions were $11 \%$ and $8 \%$, respectively. Conversely, $\mathrm{CeO}_{2}$ nanorods were more active than $\mathrm{CeO}_{2}$ nanocubes, whereas $51 \%$ of phenol conversion and $45 \%$ of TOC removal were achieved.

Compared to $\mathrm{CeO}_{2}$ nanomaterials, $\mathrm{MnO}_{x}-\mathrm{CeO}_{2}$ catalysts give very rapid phenol oxidation. $\mathrm{MnO}_{x}-\mathrm{CeO}_{2}$ nanorods could completely convert phenol and remove $98 \%$ of TOC within $30 \mathrm{~min}$, at $140{ }^{\circ} \mathrm{C}$ and $2 \mathrm{MPa}$ air (Fig. 11). The comparable activity for $\mathrm{MnO}_{x}-\mathrm{CeO}_{2}$ nanocubes could only be achieved after $60 \mathrm{~min}$. Furthermore, the adsorption experiment showed that $\mathrm{MnO}_{x}-\mathrm{CeO}_{2}$ nanorods could absorb $15 \%$ of phenol, whereas $\mathrm{MnO}_{x}-\mathrm{CeO}_{2}$ nanocubes only absorbed $7 \%$. It was seen that the addition of $\mathrm{Mn}$ could enhance the adsorption ability of $\mathrm{CeO}_{2}$ nanorods by more than 3 times. This is important, since adsorption is the primary step for the CWAO of phenol. Moreover, it was reported that high oxidation states of manganese oxide can also behave as active centers for phenol oxidation. ${ }^{36}$ Thus, it could be postulated that the addition of Mn helped to adsorb phenol and its intermediates, then $\mathrm{Mn}^{4+}$ was reduced and the adsorbed organic compounds were oxidized.

Tests on the evolution of the small-molecule intermediates for $\mathrm{MnO}_{x}-\mathrm{CeO}_{2}$ catalysts were conducted, and the results are shown in Fig. 12. There are 4 major small-molecule intermediates: formic acid, acetic acid, oxalic acid, and hydroquinone. Other intermediates, including polymeric products, are also reported in the literature, ${ }^{45}$ and can be calculated by subtracting the concentration of the remaining TOC and small-molecule intermediates. The initial TOC value for phenolic solution was about $850 \mathrm{ppm}$. For $\mathrm{MnO}_{x}-\mathrm{CeO}_{2}$ nanorods, the TOC conversion was $98 \%$, and the remaining TOC was calculated to be $17 \mathrm{ppm}$. The total organic carbon concentration of formic acid, acetic acid, oxalic acid, and hydroquinone was also converted, and turned out to be $15 \mathrm{ppm}$. Thus, it implies that the smallmolecule intermediates are responsible for $88 \%$ of the remaining TOC for $\mathrm{MnO}_{x}-\mathrm{CeO}_{2}$ nanorods. On the other hand, the small-molecule intermediates are only responsible for $32 \%$ of the remaining TOC for $\mathrm{MnO}_{x}-\mathrm{CeO}_{2}$ nanocubes. This means $\mathrm{MnO}_{x}-\mathrm{CeO}_{2}$ nanocubes have converted more phenol into largemolecule intermediates. In other words, $\mathrm{MnO}_{x}-\mathrm{CeO}_{2}$ nanocubes are less oxidative than $\mathrm{MnO}_{x}-\mathrm{CeO}_{2}$ nanorods.

The $\mathrm{MnO}_{x}-\mathrm{CeO}_{2}$ catalysts were also examined by comparing their catalytic activities at various temperatures (Fig. S3 $\dagger$ ). The results show that the catalytic activity of $\mathrm{MnO}_{x}-\mathrm{CeO}_{2}$ nanorods and nanocubes are both positively related to the reaction temperature. $\mathrm{MnO}_{x}-\mathrm{CeO}_{2}$ nanorods and nanocubes exhibit similar catalytic activity at 100 and $180{ }^{\circ} \mathrm{C}$. However, $\mathrm{MnO}_{x}-$ $\mathrm{CeO}_{2}$ nanorods become much more active than $\mathrm{MnO}_{x}-\mathrm{CeO}_{2}$ nanocubes at $140{ }^{\circ} \mathrm{C}$. This can be due to the high reducibility of 
$\mathrm{MnO}_{x}-\mathrm{CeO}_{2}$ nanorods surface, which play a more important role at moderate temperature.

In order to study the effect of oxygen partial pressure in the CWAO of phenol on $\mathrm{MnO}_{x}-\mathrm{CeO}_{2}$ nanorods and nanocubes, different pressures were investigated (Fig. S4 $\dagger$ ) for reaction. The temperature was kept at $140{ }^{\circ} \mathrm{C}$ and the catalytic activity was measured after $30 \mathrm{~min}$ reaction. When the total air pressure was set to $0.5 \mathrm{MPa}, \mathrm{MnO}_{x}-\mathrm{CeO}_{2}$ nanorods could convert $83 \%$ of phenol and $71 \%$ of TOC, whereas $\mathrm{MnO}_{x}-\mathrm{CeO}_{2}$ nanocubes could only convert $64 \%$ of phenol and $62 \%$ of TOC. When the pressure was increased, both the $\mathrm{MnO}_{x}-\mathrm{CeO}_{2}$ nanorods and nanocubes exhibited higher phenol and TOC conversions. $\mathrm{MnO}_{x}-\mathrm{CeO}_{2}$ nanorods could completely remove phenol when the total pressure was greater than $2 \mathrm{MPa}$ air. On the other hand, $\mathrm{MnO}_{x^{-}}$ $\mathrm{CeO}_{2}$ nanocubes could only achieve $95.7 \%$ phenol conversion at 3.5 MPa air. These phenomena emphasize the importance of the oxygen partial pressure to the performance of $\mathrm{MnO}_{x}-\mathrm{CeO}_{2}$ catalyst materials.

For the CWAO of phenol, the oxidizing ability of the catalyst plays a decisive role in the whole CWAO process. The TEM and XPS results indicated that the two nanorods catalysts presented a higher amount of oxygen vacancies, while the H2-TPR results suggested that both nanorod catalysts possessed higher reducibility. Generally, the lower temperature at which the reduction peak appears, the higher the oxidizing ability the catalyst possesses. Clearly, increasing the oxygen vacancies concentration can promote the oxidizing ability and thus enhance the catalytic performance for the CWAO of phenol.

\section{Conclusions}

$\mathrm{CeO}_{2}$ and $\mathrm{MnO}_{x}-\mathrm{CeO}_{2}$ nanomaterials were synthesized and used for the CWAO of phenol, whereby both $\mathrm{CeO}_{2}$ and $\mathrm{MnO}_{x}-$ $\mathrm{CeO}_{2}$ nanorods displayed superior catalytic activity than the cubic counterparts. The characterizations revealed that the catalytic activity can benefit from the presence of oxygen vacancies, which improves the reducibility of the catalyst surface and boosts the productivity of active oxygen species. The incorporation of $\mathrm{Mn}$ into the $\mathrm{CeO}_{2}$ lattice can increase the phenol adsorption ability and further promote the oxidizing ability of the catalyst. Overall, this study illustrates the importance of oxygen vacancies in cerium catalysts for the CWAO of phenol, which might provide clues for a later study on other catalysts in this field.

\section{Acknowledgements}

The authors would like to thank the financial supports from the National Key Technology Support Program of China (No. 2014BAC10B01). Prof Dr Gai would like to thank the support from key scientific and technological project of China's Shanxi Province (No. MH2014-10). The support by the Natural Science Foundation of China (21336009 and 21673187) and the Natural Science Foundation of Fujian Province of China (No. 2015J05031) is also acknowledged.

\section{References}

1 S. Yang, W. Zhu, J. Wang and Z. Chen, J. Hazard. Mater., 2008, 153, 1248-1253.

2 I. P. Chen, S. S. Lin, C. H. Wang, L. Chang and J. S. Chang, Appl. Catal., B, 2004, 50, 49-58.

3 C. B. Maugans and A. Akgerman, Water Res., 1997, 31, 31163124.

4 R. L. Autenrieth, J. S. Bonner, A. Akgerman, M. Okaygun and E. M. McCreary, J. Hazard. Mater., 1991, 28, 29-53.

5 W. Li, S. Zhao, B. Qi, Y. Du, X. Wang and M. Huo, Appl. Catal., B, 2009, 92, 333-340.

6 A. B. Ayusheev, O. P. Taran, I. A. Seryak, O. Y. Podyacheva, C. Descorme, M. Besson, L. S. Kibis, A. I. Boronin, A. I. Romanenko and Z. R. Ismagilov, Appl. Catal., B, 2014, 146, 177-185.

7 S. Yang, M. Besson and C. Descorme, Appl. Catal., B, 2015, 165, 1-9.

8 S. S. Lin, C. L. Chen, D. J. Chang and C. C. Chen, Water Res., 2002, 36, 3009-3014.

9 S. Yang, Y. Cui, Y. Sun and H. Yang, J. Hazard. Mater., 2014, 280, 55-62.

10 S. Hamoudi, F. Larachi and A. Sayari, J. Catal., 1998, 177, 247-258.

11 S. Imamura, A. Doi and S. Ishida, Ind. Eng. Chem. Prod. Res. Dev., 1985, 24, 75-80.

12 S. Imamura, M. Nakamura, N. Kawabata, J. Yoshida and S. Ishida, Ind. Eng. Chem. Prod. Res. Dev., 1986, 25, 34-37.

13 F. Arena, G. Trunfio, J. Negro and L. Spadaro, Appl. Catal., B, 2008, 85, 40-47.

14 S. X. Yang, X. G. Wang, H. W. Yang, Y. Sun and Y. X. Liu, J. Hazard. Mater., 2012, 233, 18-24.

15 F. Arena, C. Italiano, G. Drago Ferrante, G. Trunfio and L. Spadaro, Appl. Catal., B, 2014, 144, 292-299.

16 F. Arena, J. Negro, A. Parmaliana, L. Spadaro and G. Trunfio, Ind. Eng. Chem. Res., 2007, 46, 6724-6731.

17 H. Zhang, X. Liu, N. Zhang, J. Zheng, Y. Zheng, Y. Li, C.-J. Zhong and B. H. Chen, Appl. Catal., B, 2016, 180, 237245.

18 A. C. Gluhoi, N. Bogdanchikova and B. E. Nieuwenhuys, J. Catal., 2005, 229, 154-162.

19 X. Liu, K. Zhou, L. Wang, B. Wang and Y. Li, J. Am. Chem. Soc., 2009, 131, 3140-3141.

20 Y. Y. Lin, Z. L. Wu, J. G. Wen, K. R. Poeppelmeier and L. D. Marks, Nano Lett., 2014, 14, 191-196.

21 S. Agarwal, L. Lefferts and B. L. Mojet, ChemCatChem, 2012, 5, 479-489.

22 F. Lin, D. Hoang, C.-K. Tsung, W. Huang, S.-Y. Lo, J. Wood, H. Wang, J. Tang and P. Yang, Nano Res., 2011, 4, 61-71.

23 E. Aneggi, D. Wiater, C. de Leitenburg, J. Llorca and A. Trovarelli, ACS Catal., 2014, 4, 172-181.

24 X. Xing, Y. Cai, N. Chen, Y. Li, D. Deng and Y. Wang, Ceram. Int., 2015, 41, 4675-4682.

25 H. Li, G. Qi, Tana, X. Zhang, W. Li and W. Shen, Catal. Sci. Technol., 2011, 1, 1677. 
26 P. Zhang, H. Lu, Y. Zhou, L. Zhang, Z. Wu, S. Yang, H. Shi, Q. Zhu, Y. Chen and S. Dai, Nat. Commun., 2015, 6, 84488458.

27 W. Cen, Y. Liu, Z. Wu, H. Wang and X. Weng, Phys. Chem. Chem. Phys., 2012, 14, 5769-5777.

28 S. P. Wang, L. F. Zhao, W. Wang, Y. J. Zhao, G. L. Zhang, X. B. Ma and J. L. Gong, Nanoscale, 2013, 5, 5582-5588.

29 S. Liang, F. Teng, G. Bulgan, R. Zong and Y. Zhu, J. Phys. Chem. C, 2008, 112, 5307-5315.

30 G. Hua, L. Zhang, G. Fei and M. Fang, J. Mater. Chem., 2012, 22, 6851-6855.

31 E. Bêche, P. Charvin, D. Perarnau, S. Abanades and G. Flamant, Surf. Interface Anal., 2008, 40, 264-267.

32 K. Niesz and D. E. Morse, Nano Today, 2010, 5, 99-105.

33 S. Hamoudi, F. ç. Larachi, A. Adnot and A. Sayari, J. Catal., 1999, 185, 333-344.

34 D. Delimaris and T. Ioannides, Appl. Catal., B, 2008, 84, 303312.

35 P. Zhao, C. Wang, F. He and S. Liu, RSC Adv., 2014, 4, 4566545672.
36 H. Chen, A. Sayari, A. Adnot and F. ç. Larachi, Appl. Catal., B, 2001, 32, 195-204.

37 Z.-Y. Fei, B. Sun, L. Zhao, W.-J. Ji and C.-T. Au, Chem.-Eur. J., 2013, 19, 6480-6487.

38 G. Wang, B. B. Huang, Z. Z. Lou, Z. Y. Wang, X. Y. Qin, X. Y. Zhang and Y. Dai, Appl. Catal., B, 2016, 180, 6-12.

39 W. Deng, Q. Dai, Y. Lao, B. Shi and X. Wang, Appl. Catal., B, 2016, 181, 848-861.

40 H. Yao and Y. Y. Yao, J. Catal., 1984, 86, 254-265.

41 A. Trovarelli, Catal. Rev., 1996, 38, 439-520.

42 S. Zhang, X.-S. Li, B. Chen, X. Zhu, C. Shi and A.-M. Zhu, ACS Catal., 2014, 4, 3481-3489.

43 R. Zhang, K. Lu, L. Zong, S. Tong, X. Wang and G. Feng, Appl. Surf. Sci., 2017, 416, 183-190.

44 X. Tang, Y. Li, X. Huang, Y. Xu, H. Zhu, J. Wang and W. Shen, Appl. Catal., B, 2006, 62, 265-273.

45 S. Nousir, S. Keav, J. Barbier Jr, M. Bensitel, R. Brahmi and D. Duprez, Appl. Catal., B, 2008, 84, 723-731. 